\title{
PHANTOM-BASED LUMBAR SPINE EXPERIMENTAL INVESTIGATION AND VALIDATION OF A MULTIBODY MODEL
}

\author{
SIMONE BORRELLI ${ }^{1,2}$, ANDREA FORMAGGIO ${ }^{1,2}$, VITTORIA CIVILINI $^{1,2}$ \& ANDREA T. LUGAS ${ }^{1,2}$ \\ ${ }^{1}$ Department of Mechanical and Aerospace Engineering, Politecnico di Torino, 10129 Turin, Italy. \\ ${ }^{2}$ Polito ${ }^{\mathrm{BIO}}$ MedLab, Politecnico di Torino, 10129 Turin, Italy.
}

\begin{abstract}
The study of the biomechanics of the human spine is not yet developed extensively. Recent developments in this field have heightened the need for observing the spine from a comprehensive perspective to understand the complex biomechanical patterns, which underlie the kinematic and dynamic responses of this multiple-joint column. Within this frame of exigence, a joint study embracing experimental tests and multibody modelling was designed. This study provides novel insights to the segmental contribution profiles in flexion and extension, analysing different forms of sagittal-plane angles. Moreover, the validation of the multibody model contributes to defining the key aspects for a consistent spine modelling as well as it introduces the basis for simulating pathological conditions and post-orthopaedic surgical outcomes.

Keywords: Lumbar spine multibody model, Lumbar spine phantom, Multi-segment spine, Sawbones lumbar spine, Spine biomechanics.
\end{abstract}

\section{INTRODUCTION}

At present, experimental and numerical investigations are being exploited hand-in-hand to answer current biomechanical issues effectively. Therefore, the implementation of a joint approach has permitted relevant steps forward in the understanding of various biomechanical aspects, thus permitting relevant improvements in the clinical sphere, such as in surgical or biomedical procedures [1-5], implants realisation [6-12] and prosthesis design [13-17]. On the one hand, experimental analysis provides further insights into materials characterisation at different scales [18-26], objectifies clinical qualitative outcomes [27-35] and lets numerical models be validated [36]. On the other hand, numerical studies allow studying wider test scenarios and inferring physical quantities otherwise tough to figure out because of feasibility and costs reasons [37-50]. Despite human joint kinematic mechanism and intersegmental forces distribution in human joints have revealed to be a fertile topic for this twofold approach, far too little attention has been paid to investigate load-motion response of multi-level segment of human spine. So far, indeed, experimental studies have mainly reported dynamic responses of single intervertebral joints (functional spinal units [FSU]), providing scant attention to spine's comprehensive biomechanical behaviour [51,52]. Consequently, even the consistency of numerical multi-segment models has been negatively affected since in silico models can only be partially validated by those local results [53-55]. In this framework, the current work intends to provide a joint experimental and numerical contribution to the representation of multi-level lumbar spine biomechanics. In particular, this study set out to assess experimentally the global rotation of a lumbar segment phantom loaded by flexion-extension moments and to validate the corresponding multi-segmental multibody model, discerning the compressive load effects. 


\section{IN VITRO AND IN SILICO METHODS}

This study performed an experimental and numerical joint analysis, providing a comprehensive insight on the lumbar segment of human spine. The research work consisted of two complementary sections: first, a Sawbones (Sawbones Europe AB, Malmö, Sweden) lumbar spine phantom was characterised in flexion-extension motion and second, a multibody model was designed in MSC Adams environment (MSC Software, Hexagon Corporate Services Ltd., UK). The set up used during experimental tests was re-created in the numerical environment in terms of geometry and load characteristics applied; this way, a consistent comparison between experimental and in silico results was achievable.

\subsection{Experimental tests}

The experimental tests were performed on a Sawbones spinal phantom replicating not only the lumbar segment but also the adjacent vertebrae T12 and S1 (SKU3430). The phantom includes the intervertebral discs and the main ligaments; authors well distinguished the anterior and posterior longitudinal ligaments, ligamenta flava, intertransverse ligaments, supraspinal and interspinal ligaments. The latter two were created together.

Flexion and extension tests were realised by applying motion-control linear loadings with a linear-torsion test machine (Instron E3000, Instron Corporation, Norwood, MA, USA). Each test was run at a displacement rate of $20 \mathrm{~mm} / \mathrm{min}$ aiming to reduce the viscous effects given by the materials representing ligaments and intervertebral discs which could generate adverse effects; the maximum linear displacement of the machine actuator was set at $10 \mathrm{~mm}$. These parameters were settled so that they could result suitable to the aim of the work and, with the intention of future studies involving the phantom, to preserve its integrity. Both flexion and extension tests consisted of five different replicas. For each replica, the initial position of the model was not in contact with the test machine, thus resulting slacked. Consequently, since the experimental set up did not introduce an initial pre-stressed condition, the obtained force-displacement curves were re-aligned at $1 \mathrm{~N}$ threshold (less than the $2 \%$ of the maximum load recorded), compensating the initial experimental noise. The experimental set up configuration is shown in Fig. 1: the load was transmitted to the upper extremity through spherical and translational joints, suitably designed to apply a load with a constant arm with respect to the global constraint at $\mathrm{S} 1$.

The test machine-phantom couplings were specifically designed in CAD environment and 3D printed (StratasysuPrint SE Plus, Stratasys Ltd., Eden Prairie, MN, USA) to hold both ends of the lumbar phantom; moreover, they were prepared to account for the anatomical space orientation of the lumbar spine. Additionally, each test was recorded with a CANON EOS 5D MarkII camera (Canon Inc. Tokyo, Japan) in order to analyse vertebrae's kinematic patterns along the sagittal plane. To do so, markers were manually positioned on the centre of vertebral bodies and spinous processes and the planar motion tracking was post-processed by the means of GOMCorrelate software.

\subsection{Multibody modelling}

The multibody model was designed starting from the vertebral CAD geometry made available by Sawbones, which declared a correspondence with the physical model. Passive elements were added to characterise the model with the same anatomical features of the aforementioned phantom. Averaged density of each vertebra, taking care of both cortical 


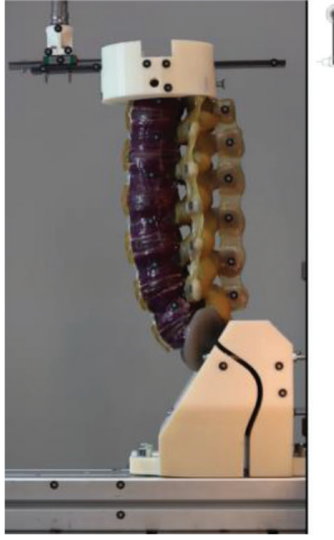

(a)

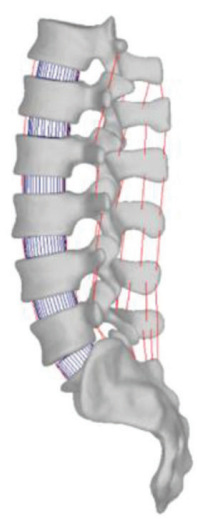

(b)

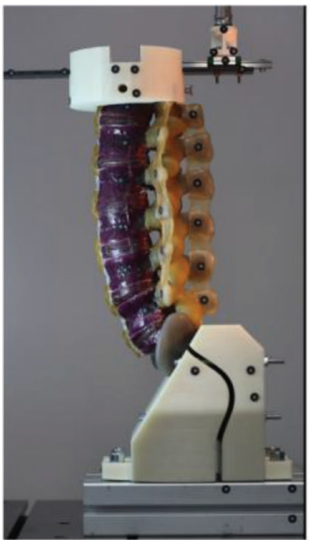

(c)

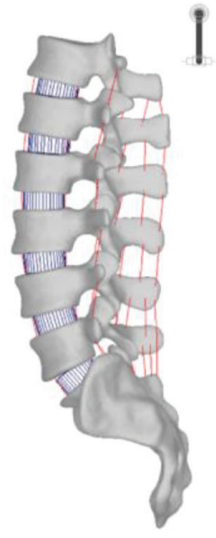

(d)

Figure 1: In vitro and in silico set up: (a-b) flexion, (c-d) extension.

and cancellous bone, was suggested by previous literature works [56-58], and the resulting masses were in accordance with previous in vitro studies [58]. Furthermore, facet joints were not only modelled as contact forces between the vertebral bodies, but attractive forces were also added oriented along the surfaces of the facets in order to limit the relative motion, accordingly to the permitted physiological ones.

Ligaments: The model distinguished the anterior (ALL) and posterior (PLL) longitudinal ligaments, ligamenta flava (LF right-left), supraspinal (SSL) and interspinal (ISL) ligaments and intertransverse ligaments (ITL right-left) for each FSU. The insertion points were positioned based on anthropometric data, and a particular focus was given to those spanning the entire lumbar segment, in order to respect the intrinsic spine's curvature. In vitro studies showed that spine's ligaments know a pre-strained condition when the spine is at upright neutral position and characterised by stress-strain curve with two main distinguishable regions: (1) non-linear segment (toe region) and (2) linear segment. Due to these aspects, it is widely spread in multibody modelling literature to reproduce ligaments' biomechanical behaviour through tension-only force constrained to follow the line of sight between their attachments [57, 59-63]. Accordingly, all the ligaments were described as a pre-tensioned spring element in parallel to a damper. The rest length $l_{0}$ was inversely computed from the distance between the defined attachment points and the pre-strains $\varepsilon_{0}$. Table 1 reports the assigned initial strain of ligaments, $\varepsilon_{0}$, and the strain at the toe-linear regions transaction, $2 \varepsilon_{r}$; all the values fall within the physiological ranges provided by in vitro studies [62, 64-66]. Starting from the suggested mechanical characterisation given by Putame et al. [2], we developed the following law to describe ligaments' stress-strain (given $\varepsilon=\frac{l-l_{0}}{l_{0}}$ ):

$$
\left\{\begin{array} { l } 
{ \varepsilon \leq 0 } \\
{ \varepsilon > 0 }
\end{array} \left\{\begin{array}{ll}
\varepsilon \leq 2 \varepsilon_{r} & -0.25 k_{n} \frac{\varepsilon^{2}}{\varepsilon_{r}}-c v_{r e l}(i) \\
\varepsilon>2 \varepsilon_{r} & -k_{n}\left(\varepsilon-\varepsilon_{r}\right)-c v_{r e l}(i)
\end{array}\right.\right.
$$


Where $k_{n}$ corresponds to a stiffness per unit strain [N], calculated from data provided by Pintar et al. [63], $c$ is the damping constant, $l$ and $v_{r e l}$ are the distance and relative velocity of ligament's attachment points, respectively. The choice to go to adimensioned stiffnesses guarantees the removal of possible biases due to different initial lengths between in vitro and in silico data. Finally, little adjustments were performed in order to make each taut length fall in its corresponding toe region range after the dynamic transitory.

Intervertebral discs: The implementation of the 6DOF of the intervertebral discs was obtained by the means of bushing force elements, typically described as non-coupled stiffness and damping matrices. Rotational and translational stiffnesses were initially extracted from reference values [58, 67-69], and then slightly adjusted with respect to the experimental behaviour revealed. Intervertebral discs were supposed at rest in the original spine stance of Sawbones CAD geometry. The orientation of discs' reference system was set for each FSUin order to comply withits local geometry. Therefore, the longitudinal axis was directed along the conjunction line of the centroids of the adjacent endplates, while the anterior-posterior axis parallel to the line joining the endplate centroid and the spinous process midpoint of the upper vertebra. The subsequent third axis was directly obtained by the previous ones to get a right-handed reference system.

Pre-load: A compressive pre-load aims to simulate the physiological compressive load that the lumbar spine encounters supporting the weight of the upper part of the body. The pre-load was designed in forms of a follower load of $800 \mathrm{~N}$, also satisfying the absence of induced transmission of moment or shear forces to the vertebrae. In the multibody environment, this kind of pre-load was created by compressing each bushing with a force acting along each disc's longitudinal axis, approximately passing through each FSU's instantaneous center of rotation [70-73].

Contacts: The only spots where contacts could take place where in correspondence of adjacent vertebrae's facet joints. Thus, deformable contacts were settled to be consistent with the particular cartilage present therein. The following relationship was adopted:

$$
F_{c}=K \delta^{e}+C(\delta) \dot{\delta}
$$

Where $K$ is the contact stiffness, $\delta$ and $\dot{\delta}$ are the penetration depth displacement and velocity, respectively, $e$ is a non-linear scaling factor, and $C$ is a sigmoid damping function based on $\delta$. Values were extracted by previous studies [53]. Due to the small entities of the displacement applied, contacts appeared during extension only at the end of the motion.

Table 1: Values of pre-strain $\varepsilon_{0}$ and strain at transaction from toe region to linear region, $\varepsilon_{l}=2 \varepsilon_{r}$. All the ligaments presented in the multibody model are listed. ALL: anterior longitudinal ligament, PLL: posterior longitudinal ligament, LF: ligamentum flavum, ITL intertransverse ligament, SSL: supraspinous ligament.

\begin{tabular}{lllllll}
\hline & & \multicolumn{5}{c}{ Ligaments } \\
& ALL & PLL & LF & ISL & ITL & SSL \\
\hline$\varepsilon_{0}$ & $5.3 \%$ & $6 \%$ & $7.0 \%$ & $4.3 \%$ & $7.0 \%$ & $-6.0 \%$ \\
$\varepsilon_{l}$ & $14.0 \%$ & $13.0 \%$ & $18.0 \%$ & $12.0 \%$ & $15.0 \%$ & $12.0 \%$ \\
\hline
\end{tabular}


Two multibody models, differing only for the presence of the compressive follower-load, were compared with the experimental results in a twofold way, dynamic and kinematic. On the one hand, flexion-extension moment-angle behaviours of the in silico models were compared to the one resulted experimentally. Experimentally, the moment was obtained from the sagittal vertical force measured by the load-cell of the testing machine multiplied by its constant arm; the angle measured, named $\vartheta_{S 1, T 12}$, was formed by the vertical axis and the line joining the center of mass of S1 (obtained from the multibody and add as a marker on the S1 constraint) and the T12 vertebral body center. The angular displacement was post-processed thanks to the motion tracking tool.

Vertebrae's range of motions (ROM) were considered in a double form: first, we measured the variation of the angle described by the vertical axis and the line joining the centres of mass of adjacent vertebral bodies $\left(\mathrm{CM}_{\mathrm{VB}}\right), \Delta \beta_{\text {rel }}$; second, we measured the variation of the horizontal angles of the lines joining the center of the spinous processes and their corresponding vertebral $\mathrm{CM}_{\mathrm{VB}}, \Delta \varphi_{h}$. The $\Delta \beta_{\text {rel }}$ provides details about the relative displacements between vertebrae, while the $\Delta \varphi_{h}$ gives evidence of the variation of orientation of each vertebra.

\section{RESULTS}

\subsection{Dynamic aspects investigation}

Experimental tests reveal an optimal reproducibility both in flexion and extension motioncontrol loads: in flexion, the momentum calculated at the maximum angular displacement $\left(2^{\circ}\right)$ shows a standard deviation of $0.15 \mathrm{~N}^{*} \mathrm{~m}$ less than the $4.4 \%$ of the corresponding mean value. Concerning the extension moment, the deviation from one replica to the other is even less $\left(0.05 \mathrm{~N}^{*} \mathrm{~m}, 2.1 \%\right)$. Figure 2 outlines, concurrently with the experimental results, the moment-angle profile of the two in silico models: the one without preload ( $n \mathrm{FL})$ and the other subjected to $800 \mathrm{~N}$ of follower load (FL). Interestingly, the rachis phantom shows a stiffer response in flexion than in extension along the small angular displacements investi-

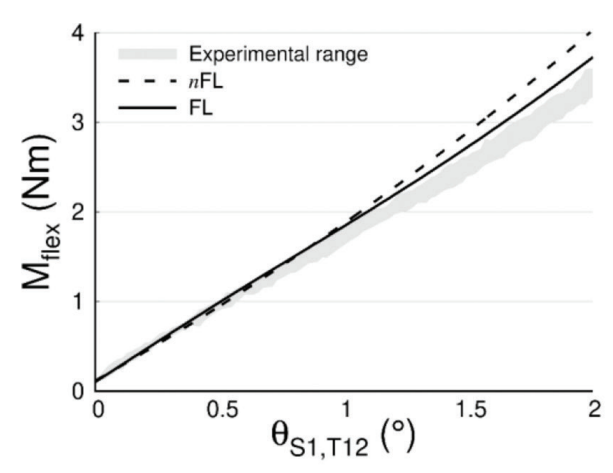

(a)

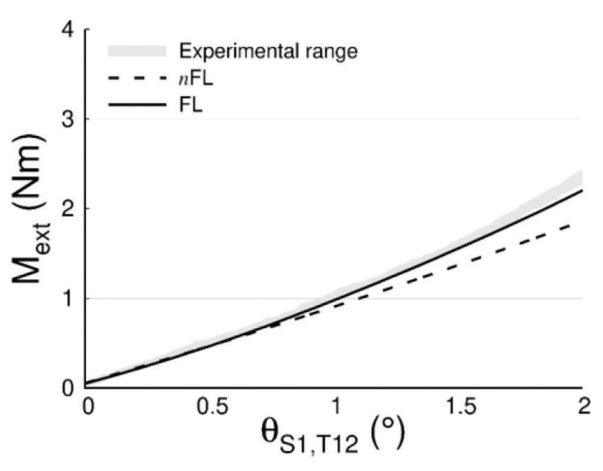

(b)

Figure 2: Bending moment applied vs angular global displacement $\vartheta_{S 1, T 12}$. The experimental range represents the range of variation obtained from the five test replicas. (a) Flexion motion; (b) extension motion. 
gated. Concerning the numerical curves, the follower load has a marked impact as the angle increases. In both cases, the application of the follower-load enables the model to describe better the experimental pattern.

At $2^{\circ}$ of flexion, the $n \mathrm{FL}$ curve diverges from the experimental mean value by a deviation of $0.8 \mathrm{~N} * \mathrm{~m}(23 \%)$. Conversely, the FL curve overestimates the experimental results with a lower error, maximum at $2^{\circ}$ of bending: $0.31 \mathrm{~N} * \mathrm{~m}(9 \%)$.

In extension, the FL curve displays a satisfactory moment-angle profile with respect to experimental data: the model load curve fell within the experimental range for most part of the plot, and the maximum separation from it, amounts to $-0.16 \mathrm{~N} * \mathrm{~m}(-6.9 \%)$. The model without pre-load assumes more deviation from all the other cases as the maximum extension moment differs of $-0.71 \mathrm{~N}^{*} \mathrm{~m}(-30.2 \%)$.

\subsection{Kinematic aspects investigation}

Finally, the kinematic analysis demonstrates good consistency between the in silico models and the lumbar phantom. Figures 3 and 4 illustrate the ROM $\left(\Delta \beta_{r e l}\right.$ and $\left.\Delta \varphi_{h}\right)$ calculated as the difference of the angles at rest configuration and at $2^{\circ}$ bended. Results show a cranio-caudally angular displacement decreasing pattern: upper vertebrae display greater mobility than the distal ones. The high reproducibility of the experimental tests is confirmed by the low variability of kinematic results, almost negligible. Furthermore, extension motion-control loading induces wider variation of angles for upper vertebrae: T12-L1 and L1-L2 $\Delta \beta_{r e l}$ are almost $1^{\circ}$ greater than in flexion. This cannot be said for the lower part of the lumbar segment, where L3-L4 behaviour is almost the same in the two circumstances and L4-L5 demonstrates a more pronounced mobility in flexion $\left(0.5^{\circ}\right.$ greater $)$. Therefore, the gradient of $\Delta \beta_{r e l}$ ranges along the spine segment reveals being higher in extension than in flexion. The chart in Fig. 4, reporting the results of $\Delta \varphi_{h}$, illustrates interesting aspects: the direction of the motion-control loading seems not varying the orientation variances, except for the extremes of the lumbar segment. Indeed, L1 registers an inclination greater of $0.6^{\circ}$ in flexion than in extension, while L5's pitch angle decreases of almost $0.5^{\circ}$ in extension.

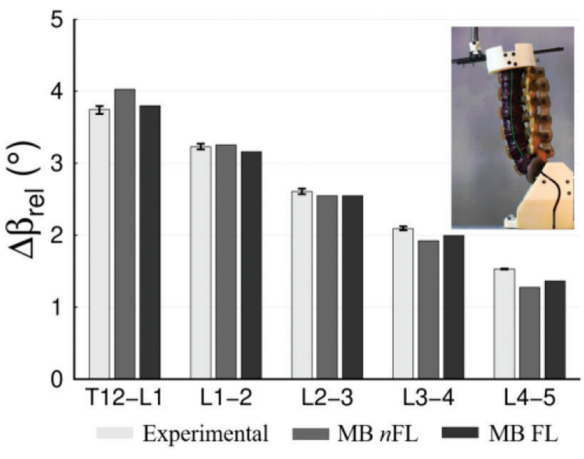

(a)

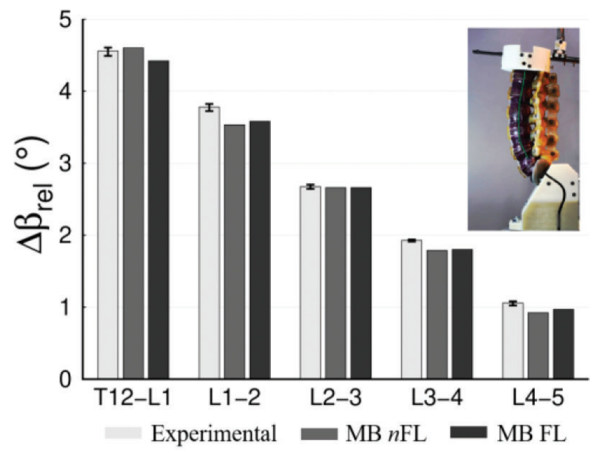

(b)

Figure 3: Variation of the angle created by two consecutive $\mathrm{CM}_{\mathrm{VB}} \mathrm{s}$ and the vertical axis, $\Delta \beta_{r e l}$. Experimental values (grey) are presented with their range obtained from the five replicas. (a) Flexion motion applied; (b) extension motion applied. 


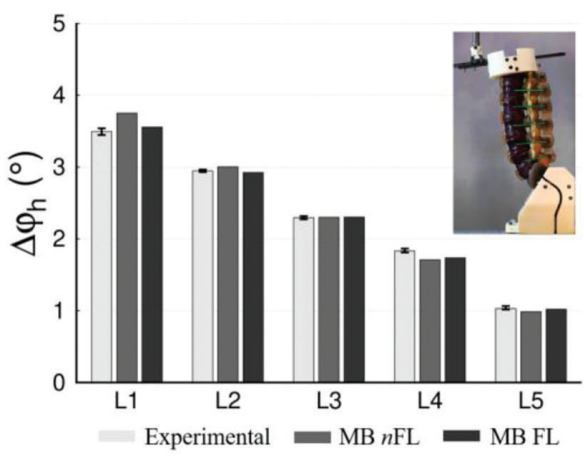

(a)

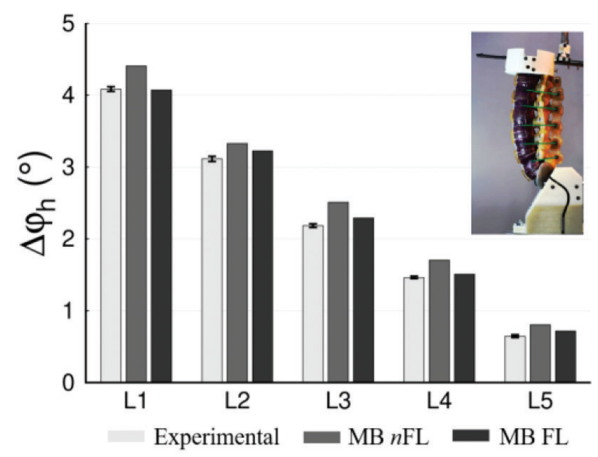

(b)

Figure 4: Singular vertebra angle, $\Delta \varphi_{h}$, formed by spinous processes - $\mathrm{CM}_{\mathrm{VB}}$ connecting line. Experimental values (grey) are presented with their range obtained from the five replicas. (a) Flexion motion applied; (b) extension motion applied.

Finally, observing the in silico models, it is possible to assess that the follower loaded multibody model reveals a very strong kinematic accuracy since in almost all cases it provides angular values included in the experimental range. On the contrary, the multibody model not pre-compressed generally shows larger estimates.

\section{DISCUSSION}

The purpose of the current study was to determine the comprehensive behaviour of the lumbar spine phantom when subjected to flexion-extension motion-control load. Moreover, two multibody models were recreated starting from its geometry to understand whether the introduction of a follower load provided greater adherence to the experimental results.

In our study, the load resulted applied to the extremity of the phantom is consistent with the ones applied during in vitro tests [70,74]. Anyway, our study makes use of a linear motion-control load to execute the torque actions on the phantom, whereas in literature, the adoption of a pure-moment loading is spread [75]: the resulted stiffer behaviour in flexion than in extension is not fully in accordance with in vitro state of art [70, 76-78]. Authors supposed that the reason of this discrepancy could be led by the way of load application, which could influence the behaviour of the spine (motion-control vs load-control). Moreover, the motion was not applied directly to the extremity of the phantom but through a constant arm. Finally, another aspect to keep into consideration is that in [77] the bending stiffness of a lumbar phantom resulted greater in flexion than in extension as highlighted in this study.

Finally, the designing of the numerical multibody models corroborates the effects of the follower load depending on the direction of the bending, already registered in in vitro and in silico studies. Anteriorly, the follower load induces an increasing bending ROM under for a given load, while posteriorly, it is the opposite.

Besides that, the introduction of the follower load makes the multibody model fit to the experimental results, both in terms of moment-angle profile and kinematic analysis and allows the numerical multibody model to be considered validated with respect to the Sawbones phantom. Therefore, starting from the validated numerical model both spinal pathological conditions and post-orthopaedic surgical outcomes can be consistently simulated. This way, future studies will be pursued to objectify their effects and compare them with the corre- 
sponding physiological results. To the best knowledge of the authors, this aspect has not been exploited yet in spinal biomechanics literature[79, 80].

\section{DECLARATION OF COMPETING INTEREST}

None of the authors have any conflicts of interest to disclose.

\section{REFERENCES}

[1] Logozzo, S., Kilpelä, A., Mäkynen, A., Zanetti, E.M. \& Franceschini, G., Recent advances in dental optics - Part II: Experimental tests for a new intraoral scanner. Optics and Lasers in Engineering, 54, pp. 187-196, 2014. https://doi.org/10.1016/j. optlaseng.2013.07.024

[2] Putame, G., et al., Surgical treatments for canine anterior cruciate ligament rupture: Assessing functional recovery through multibody comparative analysis. Frontiers in Bioengineering and Biotechnology, 7, pp. 1-11, 2019. https://doi.org/10.3389/ fbioe.2019.00180

[3] Terzini, M., Bignardi, C., Castagnoli, C., Cambieri, I., Zanetti, E.M. \& Audenino, A.L., Ex vivo dermis mechanical behavior in relation to decellularization treatment length. The Open Biomedical Engineering Journal, 10, pp. 34-42, 2016. https://doi.org/10.21 74/1874120701610010034

[4] Putame, G., et al., Application of 3D Printing Technology for Design and Manufacturing of Customized Components for a Mechanical Stretching Bioreactor. Journal of Healthcare Engineering, Article ID 3957931, 2019. https://doi.org/10.1155/2019/3957931

[5] Zanetti, E.M., et al., A structural numerical model for the optimization of double pelvic osteotomy in the early treatment of canine hip dysplasia. Veterinary and Comparative Orthopaedics and Traumatology, 30(4), pp. 256-264, 2017. https://doi.org/10.3415/ vcot-16-05-0065

[6] Putame, G., Pascoletti, G., Terzini, M., Zanetti, E.M. \& Audenino, A.L. Mechanical behavior of elastic self-locking nails for intramedullary fracture fixation: A numerical analysis of innovative nail designs. Frontiers in Bioengineering and Biotechnology, $\mathbf{8}$, pp. 1-10, 2020. https://doi.org/10.3389/fbioe.2020.00557

[7] Calì, M., Pascoletti, G., Gaeta, M., Milazzo, G. \& Ambu, R., A new generation of biocomposite thermoplastic filaments for a more sustainable design of parts manufactured by FDM. Applied Sciences, 10(17), p. 5852, 2020. https://doi.org/10.3390/app10175852

[8] Corapi, D., Morettini, G., Pascoletti, G. \& Zitelli, C., Characterization of a polylactic acid (PLA) produced by fused deposition modeling (FDM) technology. Procedia Structural Integrity, 24, pp. 289-295, 2019. https://doi.org/10.1016/j.prostr.2020.02.026

[9] Calì, M., Pascoletti, G., Gaeta, M., Milazzo, G. \& Ambu, R., New filaments with natural fillers for FDM 3D printing and their applications in biomedical field. Procedia Manufacturing, 51, pp. 698-703, 2020. https://doi.org/10.1016/j.promfg.2020.10.098

[10] Zanetti, E.M., et al., Modal analysis for implant stability assessment: Sensitivity of this methodology for different implant designs. Dental Materials, 34(8), pp. 1235-1245, 2018. https://doi.org/10.1016/j.dental.2018.05.016

[11] Dichio, G., et al., Engineering and manufacturing of a dynamizable fracture fixation device system. Applied Sciences, 10(19), p. 6844, 2020. https://doi.org/10.3390/ app10196844

[12] Lugas, A.T., et al., In vitro simulation of dental implant bridges removal: Influence of luting agent and abutments geometry on retrievability. Materials (Basel), 13, pp. 1-11, 2020. https://doi.org/10.3390/ma13122797 
[13] Putame, G., Pascoletti, G., Franceschini, G., Dichio, G. \& Terzini, M., Prosthetic Hip ROM from multibody software simulation. Proceeding of Annual International Conference of the IEEE Engineering in Medicine and Biology Society (EMBC), pp. 5386-5389, 2019. https://doi.org/10.1109/embc.2019.8856993

[14] Lugas, A.T., et al., In vitro impact testing to simulate implant-supported prosthesis retrievability in clinical practice : Influence of cement and abutment geometry. Materials (Basel), 13(7), p. 1749, 2020. https://doi.org/10.3390/ma13071749

[15] Terzini, M., Di Pietro, A., Aprato, A., Artiaco, S., Massè, A. \& Bignardi, C., Are suprapectineal quadrilateral surface buttressing plates performances superior to traditional fixation? A finite element analysis. Applied Sciences, 11(2), p. 858, 2021. https://doi. org/10.3390/app11020858

[16] Terzini, M., et al., Multibody modelling of ligamentous and bony stabilizers in the human elbow. Muscles, Ligaments and Tendons Journal, 7, pp. 493-502, 2017. https:// doi.org/10.11138/mltj/2017.7.4.493

[17] Bignardi, C., et al., Pelvic manipulator for fractures reduction. International Journal of Radiology and Imaging Technology, 9, pp. 570-580, 2018. https://doi. org/10.23937/2572-3235.1510035

[18] Pascoletti, G., Pressanto, M.C., Putame, G., Terzini, M., Audenino, A.L. \& Zanetti, E.M., On-site testing of sutured organs: An experimental set up to cyclically tighten sutures. Journal of the Mechanical Behavior of Biomedical Materials, 109, pp. 103803, 2020. https://doi.org/10.1016/j.jmbbm.2020.103803

[19] Pascoletti, G., et al., Dynamic characterization of the biomechanical behaviour of bovine ovarian cortical tissue and its short-term effect on ovarian tissue and follicles. Materials (Basel), 13(17), p. 3759, 2020. https://doi.org/10.3390/ma13173759

[20] Pascoletti, G., Pressanto, M.C., Putame, G., Terzini, M., Franceschini, G. \& Zanetti, E.M., Design of a loading system for cyclic test on sutured organs. MethodsX, 7(7), p. 100988, 2020. https://doi.org/10.1016/j.mex.2020.100988

[21] Pascoletti, G., Pressanto, M.C., Putame, G., Terzini, M., Franceschini, G. \& Zanetti, E.M., Data from cyclic tensile tests on sutured organs to evaluate creep behaviour, distraction, and residual thread strength. Data Brief, 30, p. 105644, 2020. https://doi. org/10.1016/j.dib.2020.105644

[22] Belviso, I., et al., Decellularized human dermal matrix as a biological scaffold for cardiac repair and regeneration. Frontiers in Bioengineering and Biotechnology, 8, p. 229, 2020. https://doi.org/10.3389/fbioe.2020.00229

[23] Zanetti, E.M., Perrini, M., Bignardi, C. \& Audenino, A.L., Bladder tissue passive response to monotonic and cyclic loading. Biorheology, 49, pp. 49-63, 2012. https:// doi.org/10.3233/bir-2012-0604

[24] Bhushan, B., Galasso, B., Bignardi, C., Nguyen, C.V., Dai, L. \& Qu, L., Adhesion, friction and wear on nanoscale of MWNT Tips and SWNT and MWNT arrays. Nanotechnology, 19, p. 125702, 2008. https://doi.org/10.1088/0957-4484/19/12/125702

[25] Peluccio, M.S., Bignardi, C., Lombardo, S., Montevecchi, F.M. \& Carossa, S., Comparative study of nanomechanical properties of cements used in teeth restoration. Journal of Physics: Condensed Matter, 19, p. 395003, 2007. https://doi.org/10.1088/0953$8984 / 19 / 39 / 395003$

[26] Serino, G., Gusmini, M., Audenino, A.L., Bergamasco, G., Ieropoli, O. \& Bignardi, C., Multiscale characterization of isotropic pyrolytic carbon used for mechanical heart valve production.Processes, 9, p. 338, 2021. https://doi.org/10.3390/pr9020338 
[27] Pascoletti, G., et al., A novel technique for testing osteointegration in load-bearing conditions. WIT Trans. Engeering \& Sciences, 124, pp. 187-194, 2019.

[28] Aldieri, A., et al., Osteoporotic hip fracture prediction: Is T-score-based criterion enough? A hip structural analysis-based model. Journal of Biomechanical Engineering, 140(11), Art no. 111004, 2018. https://doi.org/10.1115/1.4040586

[29] Bignardi, C., Zanetti, E.M., Terzini, M., Ciccola, A.R., Schierano, G. \& Audenino, A.L., Reliability, learnability and efficiency of two tools for cement crowns retrieval in dentistry. The Open Biomedical Engineering Journal, 12(1), pp. 27-35, 2018. https:// doi.org/10.2174/1874120701812010027

[30] Terzini, M., Bignardi, C., Castagnoli, C., Cambieri, I., Zanetti, E.M. \& Audenino, A.L., Dermis mechanical behaviour after different cell removal treatments. Medical Engineering \& Physics, 38, pp. 862-869, 2016. https://doi.org/10.1016/j.medengphy.2016.02.012

[31] D'Amelio, P., et al., Bone mineral density and singh index predict bone mechanical properties of human femur. Connective Tissue Research, 49, pp. 99-104, 2008. https:// doi.org/10.1080/03008200801913940

[32] Bellia, E., Boggione, L., Terzini, M., Manzella, C. \& Menicucci, G., Immediate loading of mandibular overdentures retained by two mini-implants: A case series preliminary report. The International Journal of Prosthodontics, 31, pp. 558-564, 2018. https://doi. org/10.11607/ijp.5589

[33] Menicucci, G., Ceruti, P., Barabino, E., Screti, A., Bignardi, C. \& Preti, G., A preliminary in vivo trial of load transfer in mandibular implant-retained overdentures anchored in 2 different ways: Allowing and counteracting free rotation. The International Journal of Prosthodontics, 19(6), pp. 574-576, 2006.

[34] Manzella, C., Burello, V., Bignardi, C., Carossa, S. \&Schierano, G., A method to improve passive fit of frameworks on implant-supported prostheses: An in vivo study. The International Journal of Prosthodontics, 26(6), pp. 577-579, 2013. https://doi. org/10.11607/ijp.3326

[35] Manzella, C., Bignardi, C., Burello, V., Carossa, S. \& Schierano, G., Method to improve passive fit of frameworks on implant-supported prostheses: An in vitro study. The Journal of Prosthetic Dentistry, 116(1), pp. 52-58, 2016. https://doi.org/10.1016/j.prosdent.2016.01.006

[36] Aldieri, A., Terzini, M., Bignardi, C., Zanetti, E.M. \& Audenino, A.L. Implementation and validation of constitutive relations for human dermis mechanical response. Medical \& Biological Engineering \& Computing, 56(11), pp. 2083-2093, 2018. https://doi. org/10.1007/s11517-018-1843-y

[37] Pascoletti, G., Catelani, D., Conti, P., Cianetti, F. \& Zanetti, E.M., A multibody simulation of a human fall: Model creation and validation. Procedia Structural Integrity, 24, pp. 337-348, 2019. https://doi.org/10.1016/j.prostr.2020.02.031

[38] Pascoletti, G., Cianetti, F., Putame, G., Terzini, M. \& Zanetti, E.M., Numerical simulation of an intramedullary Elastic Nail: Expansion phase and load-bearing behavior. Frontiers in Bioengineering and Biotechnology, 6, p. 174, 2018. https://doi.org/10.3389/ fbioe.2018.00174

[39] Falvo D’Urso Labate, G., et al., Bone structural similarity score: A multiparametric tool to match properties of biomimetic bone substitutes with their target tissues. Journal of Applied Biomaterials \& Functional Materials, 14, pp. e277-e289, 2016. https://doi. org/10.5301/jabfm.5000283 
[40] Aimetti, M., Manavella, V., Corano, L., Ercoli, E., Bignardi, C. \& Romano, F., Threedimensional analysis of bone remodeling following ridge augmentation of compromised extraction sockets in periodontitis patients: A randomized controlled study. Clinical Oral Implants Research, 29, pp. 202-214, 2018. https://doi.org/10.1111/clr.13099

[41] Pascoletti, G., Catelani, D., Conti, P., Cianetti, F. \& Zanetti, E.M., Multibody models for the analysis of a fall from height: Accident, suicide, or murder? Frontiers in Bioengineering and Biotechnology, 7, p. 419, 2019. https://doi.org/10.3389/fbioe.2019.00419

[42] Zanetti, E.M., Bignardi, C. \& Audenino, A.L., Human pelvis loading rig for static and dynamic stress analysis. Acta of Bioengineering and Biomechanics, 14, pp. 61-66, 2012. https://doi.org/10.3233/bir-2012-0604

[43] Zanetti, E.M., Crupi, V., Bignardi, C. \& Calderale, P.M., Radiograph-based femur morphing method. Medical \& Biological Engineering \& Computing, 43, pp. 181-188, 2005. https://doi.org/10.1007/bf02345952

[44] Zanetti, E.M. \& Bignardi, C., Mock-up in hip arthroplasty pre-operative planning. Acta of Bioengineering and Biomechanics, 15, pp. 123-128, 2013.

[45] Manavella, V., Romano, F., Garrone, F., Terzini, M., Bignardi, C. \& Aimetti, M., A novel image processing technique for 3D volumetric analysis of severely resorbed alveolar sockets with CBCT. Minerva Stomatologica, 66(3), pp. 81-90, 2017.

[46] Aldieri, A., Terzini, M., Audenino, A.L., Bignardi, C. \& Morbiducci, U., Combining shape and intensity dxa-based statistical approaches for osteoporotic HIP fracture risk assessment. Computers in Biology and Medicine, 127, Article no. 104093, 2020. https:// doi.org/10.1016/j.compbiomed.2020.104093

[47] Putzer, D., Nogler, M., Terzini, M., Mannara, R. \& Bignardi, C., A finite element analysis for a new short stem concept design with spherical bone interface for hip resurfacing. Journal of Mechanical Science and Technology, 9(3), pp. 923-935, 2018. https:// doi.org/10.1007/bf02916333

[48] Terzini, M., Aldieri, A., Nurisso, S., De Nisco, G. \& Bignardi, C., Finite element modeling application in forensic practice: A periprosthetic femoral fracture case study. Frontiers in Bioengineering and Biotechnology, 8, pp. 1-11, 2020. https://doi.org/10.3389/ fbioe. 2020.00619

[49] Terzini, M., Aldieri, A., Rinaudo, L. \& Osella, G., Improving the hip fracture risk prediction through 2D finite element models from DXA images: Validation against 3D models. Frontiers in Bioengineering and Biotechnology, 7, 2019. https://doi.org/10.3389/ fbioe. 2019.00220

[50] Vitale, M.C., Chiesa, M., Coltellaro, F., Bignardi, C., Celozzi, M. \& Poggio, C., FEM analysis of different dental root canal-post systems in young permanent teeth. European Journal of Paediatric Dentistry, 9(3), pp. 111-117, 2008. https://doi.org/10.1111/ipd.12587

[51] Heuer, F., Schmidt, H., Klezl, Z., Claes, L. \& Wilke, H.J., Stepwise reduction of functional spinal structures increase range of motion and change lordosis angle. Journal of Biomechanics, 40, pp. 271-280, 2007. https://doi.org/10.1016/j.jbiomech.2006.01.007

[52] Vinyas, V., Adhikari, R. \& Shyamasunder Bath, N., Review on the progress in development of finite element models for functional spinal units: Focus on lumbar and lumbosacral levels. Malaysian Journal of Medicine and Health Sciences, 16, pp. 66-74, 2020. https://doi.org/10.1097/bsd.0b013e31812e6276

[53] Abouhossein, A., Weisse, B. \& Ferguson, S.J., Quantifying the centre of rotation pattern in a multi-body model of the lumbar spine. Computer Methods in Biomechanics and Biomedical Engineering, 16, pp. 1362-1373, 2013. https://doi.org/10.1080/10255842. 2012.671306 
[54] Zheng, J., Tang, L. \& Hu, J., A numerical investigation of risk factors affecting lumbar spine injuries using a detailed lumbar model. Applied Bionics and Biomechanics, Article ID 8626102, 2018. https://doi.org/10.1155/2018/8626102

[55] Schlager, B., Niemeyer, F., Galbusera, F., Volkheimer, D., Jonas, R. \& Wilke, H.J., Uncertainty analysis of material properties and morphology parameters in numerical models regarding the motion of lumbar vertebral segments. Computer Methods in Biomechanics and Biomedical Engineering, 21, pp. 673-683, 2018. https://doi.org/10.108 0/10255842.2018.1508571

[56] Ghezelbash, F., et al., Modeling of human intervertebral disc annulus fibrosus with complex multi-fiber networks. Acta Biomaterialia, 123, pp. 208-221, 2021. https://doi. org/10.1016/j.actbio.2020.12.062

[57] Rupp, T.K., Ehlers, W., Karajan, N., Günther, M. \& Schmitt, S., A forward dynamics simulation of human lumbar spine flexion predicting the load sharing of intervertebral discs, ligaments, and muscles. Biomechanics and Modeling in Mechanobiology, 14, pp. 1081-1105, 2015. https://doi.org/10.1007/s10237-015-0656-2

[58] Christophy, M., Senan, N.A.F., Lotz, J.C. \& O'Reilly, O.M., A Musculoskeletal model for the lumbar spine. Biomechanics and Modeling in Mechanobiology, 11, pp. 19-34, 2012. https://doi.org/10.1007/s10237-011-0290-6

[59] Damm, N., Rockenfeller, R. \& Gruber, K., Lumbar spinal ligament characteristics extracted from stepwise reduction experiments allow for preciser modeling than literature data. Biomechanics and Modeling in Mechanobiology, 19, pp. 893-910, 2020. https://doi.org/10.1007/s10237-019-01259-6

[60] Panjabi, M.M., et al., Human lumbar vertebrae quantitative three-dimntional anatomy. Spine (Phila. Pa. 1976), 17, pp. 299-306, 1992. https://doi.org/10.1097/00007632199203000-00010

[61] Panjabi, M.M., Goel, V.K. \& Takata, K., Physiologic Strains in the Lumbar Spinal Ligaments. Spine (Phila. Pa. 1976), 7, pp. 192-203, 1982. https://doi.org/10.1097/00007632198205000-00003

[62] Aspden, R.M., Review of the functional anatomy of the spinal ligaments and the lumbar erector spinae muscles. Clinical Anatomy, 5, pp. 372-387, 1992. https://doi. org/10.1002/ca.980050504

[63] Pintar, F.A., Yoganandan, N., Myers, T., Elhagediab, A. \& Sances, A., Biomechanical properties oh human lumbar spine ligaments. Journal of Biomechanics, 25, pp. 13511356, 1992. https://doi.org/10.1016/0021-9290(92)90290-h

[64] Nachemson, A.L. \& Evans, J.H., Some mechanical properties of the third human lumbar interlaminar ligament (ligamentum flavum). Journal of Biomechanics, 1(3), pp. 211-220, 1968. https://doi.org/10.1016/0021-9290(68)90006-7

[65] Chazal, J., et al., Biomechanical properties of spinal ligaments and a histological study of the supraspinal ligament in traction. Journal of Biomechanics, 18, pp. 167-176, 1985. https://doi.org/10.1016/0021-9290(85)90202-7

[66] Robertson, D.J., Von Forell, G.A., Alsup, J. \& Bowden, A.E., Thoracolumbar spinal ligaments exhibit negative and transverse pre-strain. Journal of the Mechanical Behavior of Biomedical Materials, 23, pp. 44-52, 2013. https://doi.org/10.1016/j. jmbbm.2013.04.004

[67] Gardner-Morse, M.G. \& Stokes, I.A.F., Structural behavior of human lumbar spinal motion segments. Journal of Biomechanics, 37, pp. 205-212, 2004. https://doi. org/10.1016/j.jbiomech.2003.10.003 
[68] Huynh, K.T., Gibson, I., Lu, W.F. \& Jagdish, B.N., Simulating dynamics of thoracolumbar spine derived from life MOD under haptic forces. World Academy of Science, Engineering and Technology, 64, pp. 278-285, 2010.

[69] Meng, X., Bruno, A.G., Cheng, B., Wang, W., Bouxsein, M.L. \& Anderson, D.E., Incorporating six degree-of-freedom intervertebral joint stiffness in a lumbar spine musculoskeletal model - Method and performance in flexed postures. Journal of Biomechanics Engineering, 137, pp. 1-9, 2015. https://doi.org/10.1115/1.4031417

[70] Patwardhan, A.G., Havey, R.M., Carandang, G., Simonds, J., Voronov, L.I., Ghanayem, A.J., Meade, K.P., Gavin, T.M. \& Paxinos, O., Effect of compressive follower preload on the flexion-extension response of the human lumbar spine. Journal of Orthopaedic Research, 21, pp. 540-546, 2003. https://doi.org/10.1016/s0736-0266(02)00202-4

[71] Bell, K.M., Debski, R.E., Sowa, G.A., Kang, J.D. \& Tashman, S., Optimization of compressive loading parameters to mimic in vivo cervical spine kinematics in vitro. Journal of Biomechanics, 87, pp. 107-113, 2019. https://doi.org/10.1016/j.jbiomech.2019.02.022

[72] Volkheimer, D., Malakoutian, M., Oxland, T.R. \& Wilke, H.J., Limitations of current in vitro test protocols for investigation of instrumented adjacent segment biomechanics: Critical analysis of the literature. European Spine Journal, 24, pp. 1882-1892, 2015. https://doi.org/10.1007/s00586-015-4040-9

[73] Bell, K.M., Yan, Y., Hartman, R.A. \& Lee, J.Y., Influence of follower load application on moment-rotation parameters and intradiscal pressure in the cervical spine. Journal of Biomechanics, 76, pp. 167-172, 2018. https://doi.org/10.1016/j.jbiomech.2018.05.031

[74] Widmer, J., Cornaz, F., Scheibler, G., Spirig, J.M., Snedeker, J.G. \& Farshad, M., Biomechanical contribution of spinal structures to stability of the lumbar spine-novel biomechanical insights. The Spine Journal, 20, pp. 1705-1716, 2020. https://doi. org/10.1016/j.spinee.2020.05.541

[75] Widmer, J., Fornaciari, P., Senteler, M., Roth, T., Snedeker, J.G. \& Farshad, M., Kinematics of the Spine Under Healthy and Degenerative Conditions: A systematic review. Annals of Biomedical Engineering, 47, pp. 1491-1522, 2019. https://doi.org/10.1007/ s10439-019-02252-X

[76] Cripton, P.A., Bruehlmann, S.B., Orr, T.E., Oxland, T.R. \& Nolte, L.P., In vitro axial preload application during spine flexibility testing: Towards reduced apparatus-related artefacts. Journal of Biomechanics, 33, pp. 1559-1568, 2000. https://doi.org/10.1016/ s0021-9290(00)00145-7

[77] Demetropoulos, C.K., Yang, K.H., Grimm, M.J., Khalil, T.B. \& King, A.I., Mechanical properties of the cadaveric and hybrid III lumbar spines. SAE Technical Paper Series, 107, pp. 2862-2871, 1998.

[78] Panjabi, M.M., Oxland, T.R. , Yamamoto, I. \& Crisco, J.J., Mechanical behavior of the human lumbar and lumbosacral Spine as shown by three-dimensional load-displacement curves. The Journal of Bone \& Joint Surgery, 76(3), pp. 413-424, 1994. https:// doi.org/10.2106/00004623-199403000-00012

[79] Zhang, C., Mannen, E.M., Sis, H.L., Cadel, E.S., Wong, B.M., Wang, W., Cheng, B., Friis, E.A. \& Anderson, D.E., Moment-rotation behavior of intervertebral joints in flexion-extension, lateral bending, and axial rotation at all levels of the human spine: A structured review and meta-regression analysis. Journal of Biomechanics, 100, p. 109579, 2020. https://doi.org/10.1016/j.jbiomech.2019.109579

[80] Oxland, T.R., Fundamental biomechanics of the spine-What we have learned in the past 25 years and future directions. Journal of Biomechanics, 49, pp. 817-832, 2016. https:// doi.org/10.1016/j.jbiomech.2015.10.035 